\title{
Tassara: Romántico, burlador y ateo
}

\author{
Russell P. Sebold \\ Académico correspondiente \\ de la Real Academia Española
}

\begin{abstract}
No hay más que el himno del dolor humano y el sempiterno adiós a la esperanza.

Tassara, Poesías.
\end{abstract}

Una gran parte de su obra está viva y llena de posibilidades, es decir, que la lectura de sus poemas revela al hombre de hoy un mundo personal, lleno de fuego y arrebato, capaz de conmovernos con ese sortilegio, cuyo secreto sólo es poseído por los auténticos poetas.

Ricardo Gullón, «Tassara, duque de

Europa», 1946.

\section{RESUMEN}

Romántico exaltado de alma clásica, definidor y maestro de la poética romántica, ministro de España en Washington y Londres, guapo burlador, adorado de las elegantes damas que deshonraba, angustiado ateo pero persistente dialogante con Dios, Gabriel García y Tassara (18171875) es probablemente el más descuidado de los grandes poetas españoles de su tiempo. Para el estudio de estas facetas de su figura, los principales documentos utilizados son su propio verso, su extenso prólogo a sus Poesías de 1872 y la Corona poética que se le ofreció en 1878.

Palabras Clave: clásico, romántico, burlador, ateo, sensismo, panteísmo egocéntrico, religión natural.

\section{Tassara: Romantic, seducer and atheist}

\begin{abstract}
Impassioned romantic with a classical soul, definer and teacher of romantic poetics, minister of Spain in Washington and London, handsome seducer, adored by the elegant ladies he dishonored, anguished atheist but in persistent dialogue with God, Gabriel García y Tassara (18171875 ) is probably the most neglected of the great Spanish poets of his time. For the study of these facets of his figure, the principal documents utilized are his own verse, his extensive prolog to his Poems of 1872 and the Poetic Crown [necrology] that was offered him in 1878.
\end{abstract} religion.

Key words: Classical, Romantic, Seducer, Atheist, Sensism, Egocentric pantheism, Natural 
Es asombrosa la negligencia de la historiografía frente a Gabriel García y Tassara (1817-1875), literato cuyo interés resulta evidente para cualquier lector de gusto. No sólo fue un destacado poeta de la escuela romántica, sino un importante definidor del romanticismo. Sin embargo, consultar las historias literarias sobre la figura de Tassara es tiempo perdido, y prácticamente no existe bibliografía sobre él: una flojísima monografía, un artículo escrito en los primeros años de Franco, cuando no se podía hablar del ateísmo de los románticos; y por fin, una breve antología del verso del poeta ${ }^{1}$.

En 1841, al mandar a su gran amigo Juan Donoso Cortés unas meditaciones en verso sobre la devastación que aflige a toda Europa en el periodo posnapoleónico, Tassara forja un bello nombre español para el dolor cósmico romántico que aqueja entonces a los europeos inteligentes y sensibles, y a la vez describe ese estado de ánimo. He escrito el nombre indicado en cursiva

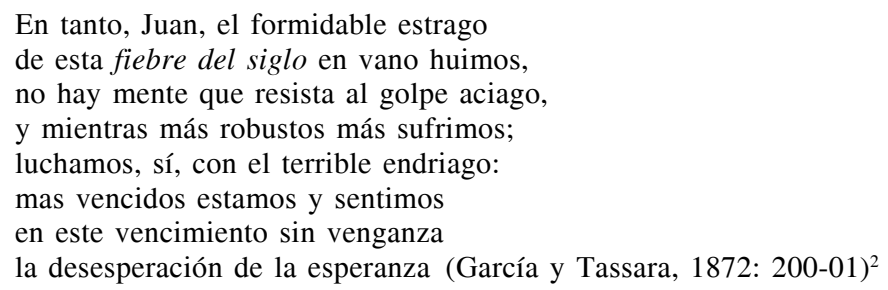

Acuñóse, en efecto, el término fiebre del siglo, de 1841, en los años en que los europeos de distintas naciones iban poniendo nombres al profundo dolor cósmico que en aquel tiempo buscaba sus víctimas en los corazones solitarios: a partir de 1833, los franceses le dirían a esa aflicción mal du siècle, y desde 1847 los alemanes le dirían Weltschmerz. La España de Tassara queda claro que estaba en ese momento completamente al tanto de las corrientes literarias europeas. Mas con el término fastidio universal de 1794 la España de Juan Meléndez Valdés se había adelantado en muchos años a los forjadores de los dos nombres decimonónicos francés y alemán de la desoladora pena

\footnotetext{
${ }^{1}$ Me refiero a las publicaciones siguientes: Mario Méndez Bejarano, Tassara. Nueva biografía crítica; Ricardo Gullón, «Tassara, duque de Europa» y la breve antología del verso de Tassara, preparada por María Palenque. Es útil esta selección, ya que es el único texto del verso de Tassara, aparte de sus Poesías de 1872, consultadas para el presente trabajo, y las revistas románticas en las que se estampó su poesía originalmente, por la mayor parte en los años 40 de la centuria XIX. Sobre las publicaciones mencionadas en esta nota, véase nuestra Bibliografía.

${ }^{2}$ El ejemplar de las Poesías tassarianas por el que cito perteneció anteriormente al conocido pensador político y estadista decimonónico Francisco Pi y Margall. La obra entera de 1872 puede consultarse en línea, en Google Books. No se hallan incluidos en el catálogo electrónico de la Biblioteca Nacional ni este volumen ni la Corona poética (1878) dedicada a Tassara y que ya consultaremos también.
} 
de la psique romántica ${ }^{3}$. Meléndez caracterizó el fastidio universal como dos vacíos concéntricos, el del corazón humano y el del universo en el que se hallaba arrojado el doliente poeta. Mas Tassara capta todo esto en el magnífico verso «la desesperación de la esperanza».

La verdadera importancia de la invención del nombre fiebre del siglo por Tassara, ya que no se trata de una innovación para España, es que con ella se nos asegura que él vive plenamente, en lo intelectual, en lo literario y en lo humano, el desgarrador anonadamiento del espíritu que amaga a los europeos de esos años, y que él está por ende capacitado para hacer de definidor del romanticismo y de testigo experiencial de la agónica pena romántica.

Tassara, quizá por primera vez en los anales del romanticismo, identificó esas dos modalidades del movimiento que Edgar Allison Peers, en su Historia del movimiento romántico español, designaría como el renacimiento romántico y la rebelión romántica. No parece nada improbable que Peers se inspirara para esas dos clasificaciones en las líneas que voy a citar ahora, pues por muy deficiente que el indicado inglés nos parezca hoy como historiador, es preciso reconocer su vasta lectura y conocimiento de los textos románticos: los famosos, los secundarios y los más olvidados.

En fin, en su prólogo sin titular de 1872, escrito en tercera persona, Gabriel apunta lo siguiente:

Desde el advenimiento del romanticismo [...], la poesía, adelantándose o siguiendo los pasos de la literatura y aun de una parte de la ciencia en general, ha seguido dos principales caminos que han determinado dos diferentes tendencias: la una, más popular, más tradicional, más peculiar de cada país, reproducción de la primitiva poesía teocrática y feudal de los trovadores, grito instintivo de las antiguas nacionalidades próximas a transformarse, y que pudiera muy bien considerarse como una especie de idealización de lo pasado; la otra más reflexiva, más razonadora, más cosmopolita [...] y que ha tenido todos los caracteres de una aspiración a lo porvenir; ambas, especialmente la última, profundamente revolucionarias en la acepción elevada de esta palabra, ambas enemigas y hasta calumniadoras de lo presente, como si hubiese momentos en que la palabra humana fuese un gas comprimido que no pudiese resonar en la sociedad sin causar explosión en la atmósfera inflamable que la rodea.

De estas dos tendencias [...], el autor siguió por instinto la última, y, prescindiendo de toda consideración puramente literaria, no ha sido de los que menos han participado en ese espíritu de invasión intelectual que la caracteriza y que tanto ha contribuido a la anarquización moral de la Europa. (1872: VII-VIII).

En un principio, Tassara no fue rebelde; pues «hasta su educación clásica le apartaba de ese camino, y en todas sus composiciones se encontrará el se-

\footnotetext{
${ }^{3}$ Acerca de la acuñación del nombre español del dolor romántico, fastidio universal, en 1794, por Juan Meléndez Valdés en su oda «A Jovino: el melancólico», véase mi ensayo de 1968, «Sobre el nombre español del dolor romántico», recogido en ambas ediciones de mi libro El rapto de la mente.
} 
llo de ese pensamiento; pero la inspiración no se manda, y, aunque creyendo siempre que tal es el carácter fundamental de sus versos — sigue caracterizándose en tercera persona-, no es él bastante hipócrita para negar que ha sentido la fiebre y con la fiebre todos los delirios de la generación a que pertenece» (1872: VIII). Por la forma en que Tassara confiesa la completa romantización que le sobrevino, queda claro que piensa en dos poemas suyos, «Clasicismo y romanticismo»y «Leyendo a Horacio». Se dirige así al insigne poeta romano, en la primera de las dos composiciones nombradas:

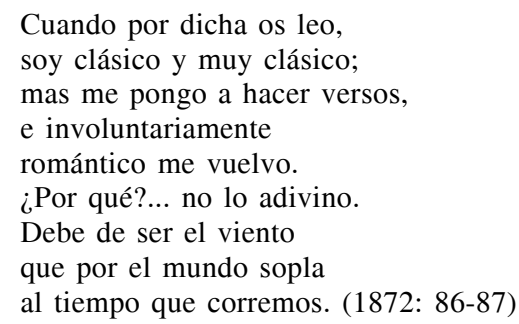

Creyendo que su carácter fundamental es clásico, Tassara ha vivido todos los delirios de la generación romántica; y siendo tan clásico, involuntariamente le salen románticos todos los versos. He aquí dos testimonios de la misma experiencia del poeta, uno en su prólogo y otro en su verso. ¿Qué significan estos textos? No se trata de eclecticismo. En ambos casos la balanza cae decididamente por el lado del romanticismo. Entonces, ¿por qué está tan presente el clasicismo en el pensamiento del que - ya lo veremos - acabará por ser uno de los más exaltados entre los románticos españoles. Se trata de un reflejo vivo del proceso histórico por el que se produjo el romanticismo, no por la revolución, como erróneamente se supuso durante muchos años, sino por la evolución (la dialéctica), según he documentado copiosamente en mi libro Lírica y poética en España, 1536-1870, así como en numerosas publicaciones anteriores.

La tarea de definidor del romanticismo en realidad no la deja nunca Tassara, porque desde el principio la viene realizando simultáneamente con su poiesis, y apenas existe un poema de Gabriel en el que no irrumpa alguna sorprendente intuición sobre la visión literaria de su generación romántica de 1840. Estas aportaciones intuitivas a la explicación del romanticismo se conectan a menudo con lo que el poeta ve como el desmoronamiento - palabra muy de su gusto- de la civilización occidental. Ese desmoronamiento se inició hacia las fechas en que un personaje de la tragedia Don Sancho García, de Cadalso, afirmó: «Dudo si el cielo de los hombres cuida» ${ }^{4}$, y en que en las Noches lúgubres, Tediato reemplazó a Dios con el Ser Supremo. Es

\footnotetext{
${ }^{4}$ Sobre este verso, véase Glendinning,1962: 50-51.
} 
decir, que tal duda de Dios se remontaba a la Ilustración materialista europea/española y a la efervescencia del materialismo científico en el setecientos.

He aquí cómo, ya en el prólogo tassariano, se proclama el derrumbe universal de la civilización, que se impone como un tema fundamental del poeta:

...a tiempos hemos llegado en que, una de dos cosas, o hay que condenarse a no hablar y a no escribir, o hay que resignarse a coadyuvar fatalmente a la obra de un siglo por esencia y potencia demoledor; porque lo mismo las afirmaciones que las negaciones, lo mismo los sistemas antiguos que los modernos, lo mismo la evocación de lo pasado, que la conservación de lo presente, que la aspiración al porvenir, todas las ideas, todas las teorías, al pasar por el crisol de la química intelectual de estos tiempos, todo contribuye a empujar y a precipitar por la pendiente del espacio y del tiempo que parecen plegarse a nuestras plantas y sobre nuestras cabezas, la carroza incendiada de aquella civilización omnipotente que los hombres de este siglo habíamos coronado con todas las coronas de una adoración verdaderamente pagánica, cuando, atribuyéndonos a nosotros mismos la infalibilidad de los oráculos que habíamos derribado, le atribuíamos a ella el poder de resolver pacífica y definitivamente el problema insoluble de las revoluciones humanas. (1872: X-XI).

Mas en quien tiene la palabra unísona con el corazón, como Cadalso o como Tassara, es imposible «condenarse a no hablar y a no escribir». Pues «triste sería haber de recelar que la musa de Goethe y Byron, de Lamartine y de Leopardi, de Quintana, de Espronceda y de Zorrilla, no tuviese ya más vocación que el silencio ante el espectáculo de un mundo que se desmorona» (1872: VII). En la página 1 de sus Poesías, Gabriel confiesa: «Tal vez levanto el vuelo al Dios que adoro, / y oso a sus plantas exclamar: ¡Quién eres!» Este Dios, o mero dios, cuya identidad se ignora, ¿será acaso el del mundo en demolición? Así, apenas concluido su prólogo, Tassara continúa preludiando un tema central a su obra poética: el desafío a la divinidad. Es más: en un pasaje de la página 56, en el poema «Himno al sol», todavía no ha dejado de anunciar temas esenciales de su poemario: el hastío y la mujer. «Al corazón cansado de sí mismo / patria será la inmensidad del mundo: / huya de mí por siempre este infecundo / goce que engendra tras del tedio el mal. // ¿No hay más felicidad que un impuro cerco / de enervantes y estúpidos placeres? / ¿No hay en el mundo ya sino mujeres / que hagan también del hombre una mujer?» ¿Un hombre demasiado cobarde para cuestionar los artículos de la fe?

En los pocos poemas que Tassara dedicó a mujeres se busca en vano una ternura auténtica o un amor que agarre y arrastre al hombre. Tassara tenía fuertes necesidades sexuales y las satisfacía con premura. Ceder, empero, a la mentalidad de la mujer, enternecerse, casarse era rendirse, emascularse, hacerse mujer. Ser sujeto de la historia, del pensamiento, de los asuntos públicos, de la diplomacia era, en cambio, ser hombre, todo un hombre. Estamos todavía en esa época machista en la que Espronceda pudo destruir la reputación de Teresa, sin perder nada de la suya. Tassara tuvo amores con una 
mujer que no le cedió a él en nada, porque ella no carecía en absoluto ni de talento ni de fuerza, y de ella decían sus colegas masculinos con intención elogiosa que para mujer era mucho hombre: me refiero a Gertrudis Gómez de Avellaneda, y no cedieron, ni ella ni el duque de Europa, y cuando les nació una niña de sus relaciones sexuales, Gabriel rehusó ir a verla. Es más: al morirse la pobre criatura, Brenilde, a los siete meses, el poeta no contribuyó ni un céntimo a los gastos de su entierro.

Las damas de la sociedad internacional de Washington, donde Tassara estuvo de ministro de la reina de España durante diez años, estaban deslumbradas por las elegantes maneras y los poéticos aires del guapo representante de Su Majestad, Isabel II; pero allí, lo mismo que en su tierra, Gabriel siguió la práctica de amarlas y abandonarlas. De nada sirvieron las cartas manchadas con lágrimas de la joven washingtoniana Magdalena Goddard: «el grito de mi tortura desea impresionar un corazón tan cruel» (Méndez Bejarano, 1928: 58). También abandonó Tassara a Magdalena; y en cuanto se lo pidiera su fisiología, procedería a buscarse otra víctima de sus hechizos varoniles. En Londres representó los intereses de España durante pocos meses, y era ya algo menos joven y fogoso.

Ternura sí hay en la poesía de Tassara, mas no es ternura de un varón hacia una mujer amada, sino el deseo egocéntrico, habitual en el romántico tipo burlador, de descansar de sus aventuras en la ternura femenina de una antigua conquista.

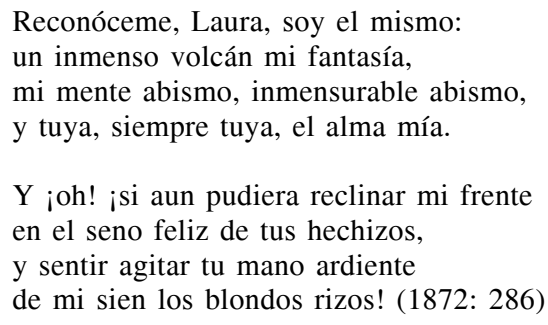

¿Blondos? ¿Fantasía de vanidoso poeta dandi? ¡Tassara tenía el pelo negro! Como frontispicio de los «Apuntes biográficos», en la Corona poética ofrecida a Tassara, se reproduce un dibujo sepia del Gabriel guapo, digno, elegante y orgulloso, de entre treinta y cinco y cuarenta y cinco años de edad, nariz aguileña, ojos claros, bigote, hoyuelo en la barbilla, levita con solapa pequeña, camisa con cuello alto y corbata de lazo.

Ni relaciones largas, ni sentimentalismo, ni ceremonias del cortejo, no cabe mejor ejemplo del desprecio de Tassara por las formas vacías del ritual romántico que lo que respondió a una dama que le pidió inscribiera algunos versos en su álbum: 


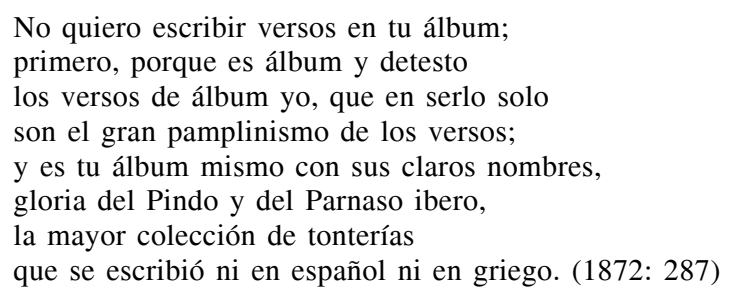

Ningún hombre ni mujer civilizada de nuestro tiempo dejaría de condenar la conducta de Tassara con la mujer. Mas el crítico literario que se ocupe cual moralista de las acciones reprehensibles de un gran poeta del pasado es aquel a quien le duele la conciencia y fracasa en su misión de crítico. Pues la finalidad de la crítica no es el castigo, sino la elucidación. El Canto a Teresa, de Espronceda, para con la mujer es seguramente uno de los poemas más crueles del mundo; y sin embargo, es probablemente, considerada sólo como composición artística, el poema más hermoso del romanticismo mundial ${ }^{5}$. Pero dejemos ya a un lado el tema amoroso, porque Tassara no nos dejó otro Canto a Teresa, y ocupémonos de los restantes temas que quedan anunciados.

Los caballeros de los que Gabriel copió sus ademanes, gestos y suspiros de hastío - todo ello recogido en El hombre fino al gusto del día y en las páginas de Larra- hacía tiempo que se habían hastiado de las rebuscadas delicadezas de los tés y los saraos ${ }^{6}$. Y tampoco tarda el sevillano trasplantado a Madrid, a Washington, a Londres en empalagarse. Recordemos estos versos ya citados: «Huya de mí por siempre este infecundo / goce que engendra tras del tedio el mal. // ¿No hay más felicidad que un impuro cerco / de enervantes y estúpidos placeres?» (1872: 56). Este triste camino lo recorrerá repetidas veces Gabriel. El remedio piensa descubrirlo huyendo, viajando. «Al corazón cansado de sí mismo / patria será la inmensidad del mundo» (ibíd.). Corre Gabriel, corre, corre... ¿y qué? Contrae la fiebre del siglo, porque llegado al final del camino, todo es lo mismo, «un himno de agonía / a esta Europa que corre a suicidarse (1872: 1).

Hace más de ochenta años, Américo Castro afirmaba con plena razón que la cosmovisión romántica es un panteísmo egocéntrico en el que el poeta desempeña el papel de la divinidad ${ }^{7}$. Utilizando las confesiones de Tassara,

${ }^{5}$ Véanse mis ensayos sobre el Canto a Teresa: «Misoginia y exculpación: el Canto a Teresa». en mi libro Concurso y consorcio: letras ilustradas, letras románticas; y «Espronceda, machista y arrepentido», en mi libro Ensayos de meditación y crítica literaria.

${ }^{6}$ Sobre el libro aludido y las costumbres explicadas en él, véase mi ensayo «Fígaro y el hombre fino», en mis Ensayos de meditación y crítica literaria.

${ }^{7}$ «Ce qui s'appelle en soi romantisme, est une métaphysique sentimentale, une conception panthéistique de l'univers dont le centre est le moi et qui, sous forme systématique ou désordonnée, intensive ou atténuée, anime toute la civilisation européenne au début du XIX siècle» (Castro, 1922: 13). De hecho, esa metafísica animaba la civilización europea a partir de 1770. 
vamos a reconstruir su panteísmo egocéntrico, la cosmología de ese mundo romántico que reflejaba lo más íntimo, angustiado y temblante de su alma.

García y Tassara representa probablemente mejor que ningún otro español la atormentada progenie de la Ilustración dieciochesca, en cuyas inmensas latitudes la observación científica había librado ardorosas batallas contra todos los sistemas filosóficos y todas las sectas religiosas. ¿Cómo era la vida espiritual de un joven de veinte años hacia 1837, imbuido, por un lado, del catequismo e instruido en escuelas y universidades donde los profesores eran mayoritariamente religiosos, pero expuesto, por otro lado, en intensas lecturas solitarias, a la más avanzada opinión científica europea? Hay momentos - lo veremos a lo largo del resto de este trabajo- en los que las dudas y angustias religiosas y la asombrosa iconoclastia de Tassara se acercan a las de Unamuno.

Anticipémonos al pleno desarrollo de nuestro tema poniendo aquí muestras de la aflicción espiritual de Gabriel. «Los himnos se acabaron. / [...] La fe me falta». «Hay un Dios, me lo dice el alma mía / [...] / ¿En quién he de creer si en ti no creo? / ¿Y a quién me he de volver si tú me engañas?». «Mi sistema son todos los sistemas; / el sistema de Dios es el que ignoro». (1872: 206-207, 252, 371). El hastío y la fatiga del dandi romántico no dejan de hermanarse directamente con estas dudas y titubeos de la fe: son en gran parte el producto de ellos.

En el poema «Meditación religiosa», Tassara cuenta que en su tiempo él, cual todos los jóvenes de cierta ilustración, sentía la llamada del examen y el razonamiento científicos: «En mi razón la duda / se apacentó algún día; / yo quise ver la realidad desnuda / del mundo en que vivía» (1872: 23). «Y a mi alma le es bastante / la ciencia y la verdad que está delante» (1872: 33), parece haberse asegurado una y otra vez, aunque en vano. ¿Y qué es lo que por último le reveló esa ciencia, al parecer tan adecuada para iluminar todos los caminos y todos los secretos?

\author{
Transformación sin límites del lodo \\ en que mi planta hundía, \\ naciendo todo y pereciendo todo \\ allí donde nacía;
}

Eso fue el mundo para mí. Un abismo, y en ese abismo nada: yo llevé la impiedad al fanatismo, la voz del alma ahogada. (1872: 23)

«Y sin que ya la realidad me asombre —lamentó- / dudé del hombre al conocer al hombre» (1872: 98). Los hombres dudando de los hombres, así como de sus almas y de su común Creador, «el linaje humano / de su seno abortó razas de ateos» — reconoce Tassara en su poema «Canto bíblico» (1872: 179)—. El desilusionado escrutador del cielo, la tierra y el hombre empieza 
ya a comprobar los efectos de su desilusión plasmados en el cielo, la tierra y el hombre; y viéndose reducido a poeta maldito halló la que fue acaso la primera o la esencia de todas sus elocuentes metáforas del hastío romántico:

\author{
Hórrida simpatía \\ el alma adivinaba \\ entre la estéril sequedad del suelo \\ y la aridez del corazón. No hallaba \\ de amor o de amistad un sentimiento \\ ni en los otros ni en mí; y en torno, en torno \\ yermado y triste y sin vigor el campo. (1872: 136)
}

Los que os ocupáis de cuestionar cielo, mundo y humanidad, «vivís en la región del pensamiento / toda una eternidad cada momento» (1872: 141). Vivís todas las dudas, todas las esperanzas, todas las aspiraciones, todas las caídas de la raza entera: intolerable proceso existencial. ¡Qué cruel es consigo quien piensa! «iOh! quién pudiera con su propia mano / arrancar de su frente el pensamiento!» (1872: 243). Éste sería el único remedio, concluye Tassara, meditando un triste día de otoño, cuando su mal son ya miles de males. Al poeta romántico suicida Juan Antonio Pagés (†1851) le afligió el mismo mal: «La lepra del pensamiento llegó a contaminar el tronco vital de los sentimientos, el sentimiento de la existencia» (Pagés, 1852: 30; cursiva mía) ${ }^{8}$.

Hacia 1726, Benito Jerónimo Feijoo y Montenegro caracteriza la poesía francesa de cuerda y lánguida, y al contrario, encuentra en la española y la italiana un noble entusiasmo. Sigue comentando las dos posturas poéticas con emoción: «Quien quiere que los poetas sean muy cuerdos, quiere que no haya poetas. El furor es el alma de la poesía. El rapto de la mente es el vuelo de la pluma» (Feijoo, 1769; 294). De este pasaje viene el título de un libro mío sobre el verso del siglo XVIII, citado más arriba, y escogí esas palabras para título porque aparte de la belleza del conjunto de ese trozo intuitivo, me llamó la atención la agudeza de Feijoo al escoger, en el umbral de un siglo filosófico y científico como el setecientos, una palabra como mente al representar el vuelo de la poesía. Muy bien hubiera podido decir: El rapto de la inspiración, del numen, del corazón, etc. es el vuelo de la pluma. Mas con mente también se alude a lo racional, lo lógico, lo científico de la actividad intelectual humana, y en el siglo XVIII ciertos poetas encontrarían inspiración de gran vuelo en las ciencias (Luzán, Viera y Clavijo, Meléndez Valdés), así como en estudios rigurosos como las reglas de la música y las de la poesía (Luzán, Iriarte).

Tassara, voraz amante de los libros, debió de leer y meditar en el citado pasaje feijoniano sobre la poesía. Pues, en su poema «El crepúsculo», Gabriel glosa el interesante comentario de Feijoo y lo adapta a su tiempo:

\footnotetext{
${ }^{8}$ Juan Antonio Pagés se suicidó en Barcelona a los veintiséis años en 1851, dejando 794 páginas de obras poéticas, ensayísticas y filosóficas. Véase nuestra Bibliografía.
} 


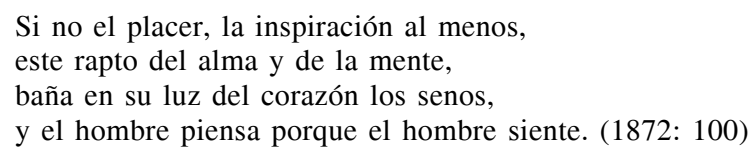

A lo largo del siglo XVIII el sensismo inductivo fue, por un lado, reemplazando el racionalismo deductivo, y por otro lado, compitiendo y colaborando con él. Esa reciente fase de la historia de la filosofía Tassara la capta sucinta y exactamente en el cuarto de los versos que acábanse de copiar: «y el hombre piensa porque el hombre siente». Recordemos, por contraste, lo que decía René Descartes doscientos años antes, con un verbo muy diferente, en su célebre Discours de la méthode: «je pense, donc je suis»; pienso, luego soy (Descartes, hacia 1925: 35-37). El dominio mental que corresponde a la razón y el pensamiento, en la revisión tassariana de la metáfora de Feijoo para la inspiración, se representa por la voz mente, y todas esas actividades más intuitivas y creativas del científico o el poeta, que responden a los sentidos, quedan representadas por la voz alma en el ya citado verso: «este rapto del alma y de la mente».

Tal verso y el largo proceso mental europeo que llevó a la reformulación de la frase feijoniana, «rapto de la mente», nos importan por ser sintomáticos a la vez de la profunda sacudida psicológica del paso de la visión deductiva racionalista, plana, blanca y negra, cartesiana, del mundo a la cosmovisión inductiva sensista, multicolor, multidimensional y materialista, a lo Locke y Condillac, típica de los nuevos pensadores, poetas y pintores que descubrirían en el objeto material de su estudio, no sólo las soluciones y delicias que les habían atraído en primer término, sino la fuente de dudas, pesares y aun tentaciones mortales que ni aun habían sospechado quienes miraban el mundo con ojos cartesianos y escolásticos. En relación con esto, puede consultarse el capítulo 13, «La historia filosófica del yo romántico», de mi libro Lírica y poética en España, 1536-1870, en cuyas páginas cito pasajes descriptivos de 1699 del discípulo sensista de Locke, conde de Shaftesbury, hombre más sensible, más poeta que su maestro, en cuyas líneas el lector juraría haber descubierto las primeras fuentes de versos como los ya citados tassarianos: «Hórrida simpatía / el alma adivinaba / entre la estéril sequedad del suelo / y la aridez del corazón...».

Aun en sus momentos de aparente plenitud amorosa, Tassara siente -es como si lo palpara físicamente- «el peso, la miseria / del espíritu preso en la materia». Cito el poema «A Elvira»:

\footnotetext{
Es cuando siento más aquí en mi seno esta de un sumo bien sed infinita, la mezquindad de nuestro ser terreno, el rugido del alma que se irrita, el peso, la miseria del espíritu preso en la materia. (1872: 172)
} 
¿Con qué derecho protesta este mal siervo del Señor? Ninguno. Si él palpa la materialidad, la oquedad, el vacío de todas las cosas, tiene en sí toda la culpa. Es un materialista voluntario, ya que optó por estudiar la materia con todas las luces de la ciencia, y se queja con Dios de la aflicción que él mismo se buscó:

Dame tu arpa joh Señor! El alma mía, desdeñosa del mundo y de los hombres, mi alma ¡oh Dios! mi alma ¡oh Dios! está vacía y a expresar su dolor no encuentra nombres. (1872: 178)

¿Ni aun el más santo de todos los nombres, que aun él pronuncia en esta ocasión? En otro momento de ansia y de duda, echó el siguiente juramento « Maldecido esqueleto de la ciencia!» (1872: 338).

¿Qué elementos de fe le quedan al hombre ilustrado cuando por lo visto se ve asediado por la desilusión absoluta? Diría acaso Tassara que le quedan, cuando menos, su yo, su carácter y sus sentidos. Y en esto ¿qué objeto de culto, qué religión ha de encontrar? «Leyendo a Horacio», musita Gabriel:

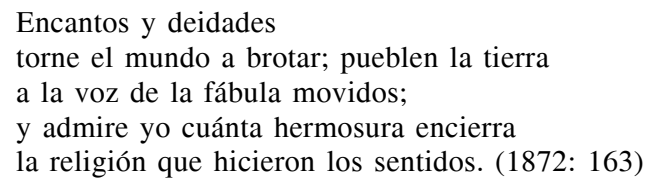

Resulta que sí le queda una religión, una fe, es la de las artes, levantadas sobre los cinco talentos corporales del hombre con que se crean. A la conclusión del mismo poema, se le presenta otra religión, no como sorpresa, sino simplemente como plasmación final de una idea que parece natural venga desde hace tiempo elaborándose en la mente de un hombre de carácter como el de Tassara:

¿Dirélo yo que en el orgullo adoro la última religión del alma fuerte? (1872: 170)

Armado de sus sentidos y de su orgullo, el desilusionado, iconoclasta y dandi romántico sale a la conquista del cielo poético. Mas para el sevillano Tassara cielo poético no es en absoluto y nunca fue esa hermosa, delicada y sensual naturaleza realista de égloga que captaron con finura en su verso los poetas sensistas de las dos escuelas poéticas dieciochescas de Salamanca y Sevilla, y que como alegre decorado persiste en muchas obras románticas. El concepto de cielo lo más atractivo que tiene para Gabriel es soledad, frialdad, transparencia, lluvia, niebla. Como objetos imitables, las flores, los prados, los bailes y otras costumbres alegres son mucho menos interesantes que los páramos, las montañas y las tormentas. 
Lo andaluz pintoresco es extrañamente ajeno al carácter de este sevillano. Algún desastre ocurrido en sus primeros años en Hispalis, algún profundo odio de clase, algún resentimiento personal que le amargara la existencia debe de estar a la base. «Mi paterna Andalucía / [ha sido] para mí inhospital, para mí ingrata», afirma Gabriel en su poema póstumo «A Ávila». En el mismo poema, dedicado a Saturnino Bugallal, una página más abajo, Tassara continúa así:

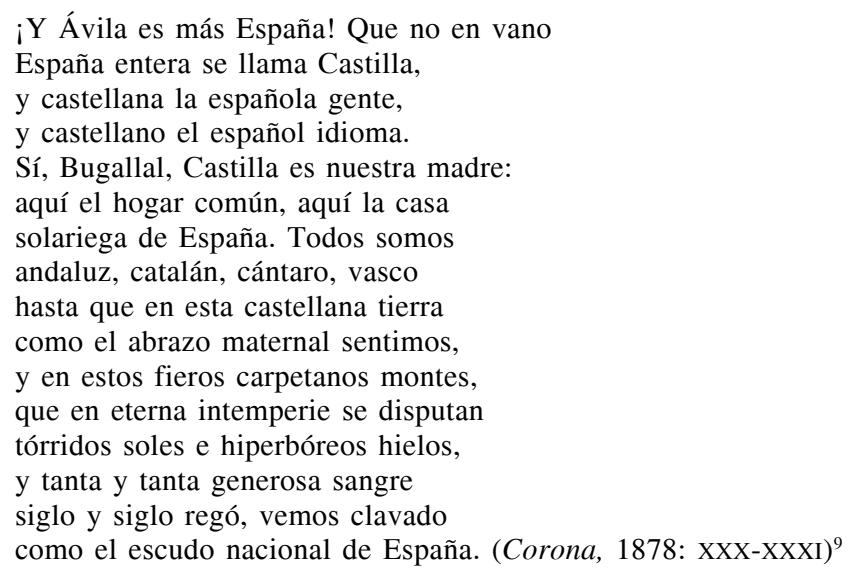

Seguramente le habría encantado este poema a Unamuno. Entre los versos póstumos tassarianos hay también un soneto, destacado por Ricardo Gullón en 1946, el cual seguramente habría resultado aun más atractivo para Unamuno:

Cumbres de Guadarrama y de Fuenfría,
columnas de la tierra castellana,
que, por las nieves y los hielos, cana,
la frente alzáis con altivez sombría.
Campos desnudos como el alma mía,
que ni la flor ni el árbol engalana.
Ceñudos al nacer de la mañana,
ceñudos al morir de breve día.

Al fin os vuelvo a ver tras larga era, os vuelvo a ver con el latido interno del patrio amor que vivo persevera.

Para mí y para vos llegó el invierno. Para vos tornará la primavera, mas mi invierno ¡ay de mí! será ya eterno! (Corona, 1878: XXVII)

\footnotetext{
${ }^{9}$ Sevilla, no obstante, nunca ha titubeado al reclamar la paternidad del ilustre poeta, especialmente después de su muerte.
} 
Trátase de la visión del mundo de un hombre soltero y solitario, sin familia, que no tenía sino dos amigos entrañables: el político, orador y ensayista Juan Donoso Cortés ${ }^{10}$ y el político y poeta Salvador Bermúdez de Castro $^{11}$. Tampoco tenía Tassara un cálido refugio donde recogerse al final de sus días en Madrid: ocupaba solo unas habitaciones en el número 16 de la calle de Serrano (Méndez Bejarano, 1928: 197). Se conservan unas líneas, de efecto patético, de Amós Escalante, sobre el triste pasatiempo diario del demasiado pronto gastado Tassara.

A la sala de periódicos del Ateneo de Madrid solía concurrir en las horas de menos gente un lector, que en su porte y facha mostraba señales de gustos varios y profesiones distintas entre sí, cuando no contradictorias y opuestas: algo de militar, mucho de poeta inspirado y contemplativo, no poco de sujeto práctico y activo, usado en los negocios y luchas de la vida y bastante de gentilhombre, a quien son familiares costumbres y modales de cortesanas fiestas y salones.

Su estatura regular, su aire noble, la cabeza caída a intervalos sobre el pecho, el paso recio y no muy seguro, como de quien ve poco o desconfía del piso. Su traje, cual convenía a sus años, recio y varonil, ni falto ni presumido de elegancia, con indicios de gusto propio e independiente, que ni obedece a la moda, ni la contradice y niega, y menos se abandona al capricho [...]: levita negra, larga y abotonada; pantalón gris y la corbata negra también, revuelta, apretada al cuello y alta, más, al aparecer, por cautela de doliente que por resabio y memoria de días $\mathrm{y}$ atildamientos juveniles.

Fino de facciones, pálido de color, bien puesto de bigotes, trigueña y clara la tez ya marchita por años y penas, haciéndole vivos y expresivos los ojos, encendidos por la incesante labor del pensamiento, asomando en su luz febril esos destellos elocuentes y dolorosos de la pupila que vienen a ser el grito mudo de hondos e incurables padecimientos físicos. Y cuando acontecía quitarse el sombrero, mostraba el cabello negro todavía embastecido a trechos, erguido y revuelto de manera que parecía indicar no haber sido, tiempos atrás, el adorno menos preciado de su persona. (reproducido en Méndez Bejarano, 1928: 197).

Todo esto lo vio largos años antes como en una visión un compañero, el dramaturgo, poeta y político Antonio Hurtado y Valhondo, que falleció en el mismo 1875 que Tassara:

¡Cómo se retrataba en tus pupilas el sombrío pesar y el hondo tedio que exhala el alma cuando triste y sola suspira por el cielo!

${ }^{10}$ Recuérdese que Tassara sufría su fiebre del siglo junto con Donoso Cortés.

11 «...Tus versos leo, / tus versos, Salvador, que amé cual míos» (1872: 334). Bastará citar una sola frase de este amigo de Tassara para mostrar lo que tenían en común: «Sólo en las cabezas de los idiotas y en las almas de los ángeles no hallan cabida las pesadas cadenas de la duda» (Bermúdez, 1840: II). Puede consultarse mi artículo «Raza de ateos». La generación romántica de $1840 »$ en mi ya mencionado libro Concurso y consorcio: letras ilustradas, letras románticas. 


\author{
Cuando por vez primera ante mis ojos \\ tu figura pasó, sentí en el pecho \\ algo que presagiaba tu ruina \\ en brevísimo tiempo. \\ Te vi en Sevilla, y casi niño eras; \\ ¡un niño! poco más; pero en tu gesto \\ ya se marcaba lo viril del hombre \\ y el aplomo del viejo. (Corona, 1878: 114)
}

Interiormente, moralmente, éste es el hombre que Gabriel lleva siendo desde hace dos o tres decenios, desde que publicó la mayor parte de su obra. Un día de otoño hace estos versos: «Tristeza al alma mía / inspira el mundo ya. Tristeza al alma / que respondiendo al estertor del mundo / voz en este profundo / silencio busca y vida en esta calma. / Al alma que en sí misma se repliega, / que está del mundo en la tristeza triste, / y a su dolor y soledad se entrega, / y a sentirse penar dura y existe» (1872: 231). Lo que inquieta a este poeta envejecido antes de tiempo son las cuestiones y causas radicales de la existencia: ¿Quién es Dios? ¿Quién es el hombre? ¿Cuál de los dos inventó al otro? ¿Cree el ateo en Dios? ¿Duda el creyente de Dios?

La cosmovisión panteísta egocéntrica del romanticismo exaltado es el punto de partida más adecuado para una discusión de la relación entre la divinidad y el sujeto humano porque su postura sume a los dos interesados en lo más estrecho del tema. Danse dos ejemplos del fácil acceso del romántico a la presencia de Dios en el poema «El crepúsculo», uno ya en la primera estrofa: «Mi Dios soy yo, mi sociedad yo mismo. / Ni su voz, ni su imagen, ni su nombre. / Lejos de mí la sociedad y el hombre» (1872: 94). Dos páginas más abajo, Tassara escribe: «Yo soy mi propio Dios solo en mi cielo», quizá la más sucinta de todas las descripciones de la postura del romántico ante el universo. Queda claro que tal irreverencia ante la divinidad se le ha hecho posible y aun natural a Tassara por el desasosiego provenido de su herencia materialista dieciochesca. De ahí asimismo el ateísmo en el que cae en los momentos en que no le sostiene su desesperada esperanza de hallar a un nuevo dios o confirmar al viejo.

No sabe Gabriel con quién habla cuando reza, y esto le desespera. Concluye, por tanto, de modo muy extraño su poema Dios:

¡Señor! ¡Señor! te escucho. ¡Señor! ¡Señor! te veo,

¡Oh tú, Dios del creyente! ¡Oh, tú, Dios del ateo!

Aquí tienes mi alma... Tómala... Tú eres Dios. (1872: 15)

Si podemos imaginarnos un Unamuno que, cuando no estudie, medite o rece, sea dandi y frecuentador de la sociedad elegante de las grandes capitales del mundo, hele aquí en la contradictoria figura de Tassara. Por los versos citados, no sabemos si el Dios que Tassara acepta, al final de su corta 
composición de dieciséis alejandrinos titulado Dios, será el Dios del creyente, o bien el Dios del ateo. Y al final probablemente no importa cuál sea, si tiene razón Unamuno en su famoso aserto de que no hay más férvido creyente que el ateo, pues nadie lucha contra un enemigo inexistente, y el ateo dedica toda su existencia, alma y cuerpo, a vencer a Dios.

Tassara puede ser irónico, y muy irónico, sarcástico, y muy sarcástico; mas no es frívolo ni bromista. Apenas tendrá sentido del humor, sobre todo cuando se trata de algo que le roe el corazón como el ateísmo del aspirante a creyente. Es un problema personal, pero lo es también nacional e internacional, y todo ello radica en el conflicto entre el cristianismo y el materialismo científico, entre Dios y los ateos. «Morir la Europa siento» (1872: 197). ¿Por qué? ¿Qué le pasa a esa generación europea? Gabriel responde en la misma página: «Raza de ateos que a luchar nacimos, / luchamos contra el cielo y sucumbimos». Nada en absoluto le solaza esa victoria, porque es de la jerarquía católica. ¿Le habría consolado la victoria de los ateos «creyentes» a lo Unamuno? Suficientes feligreses de esa fe había, pues «el linaje humano / de su seno abortó razas de ateos» (1872: 179), ¿Fe, los ateos? La duda pensativa de los ateos, ¿no es al menos tan espiritual como la apatía de la jerarquía, el clero y la multitud de bautizados de la Iglesia oficial?

Las imágenes poéticas presentes en las composiciones de Gabriel sirven para representar al mismo tiempo su cosmovisión romántica y su iconoclastia atea. Pienso, por ejemplo, en los ya citados trozos del poema «El crepúsculo» en los que Gabriel preside como Dios su propio cielo. Veamos algún ejemplo adicional. En un momento determinado, Dios ha dispuesto de Gabriel, pero la criatura no está a disgusto en el mundo solitario que se ha creado:

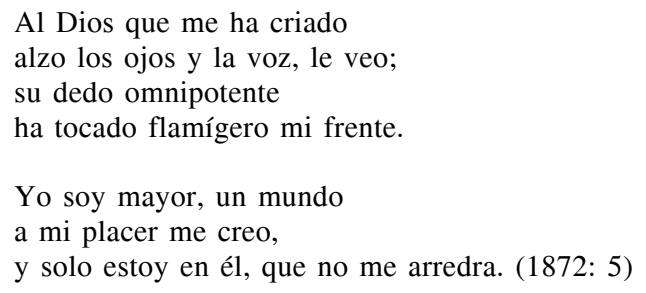

«¿Dónde encontrar la valla / de esta infinita soledad?»(1872: 163), se pregunta otro día. Pero Tassara, como todo auténtico poeta, comparte con Dios, el don de la creación, y resuelve en el acto el vacío de esa soledad. «La tierra brota genios a mi paso, y una familia de deidades creo» («Leyendo a Horacio», ibíd.).

Aparte de las posturas atea y poética para el examen de la divinidad y la fe, Tassara ensaya otras. Aquí entran de nuevo a desempeñar un papel los sentidos corporales del hombre y el sensismo, junto con la intuición. Por mucho que titubeen los sentidos ante el desastre, son siempre nuestra más 
firme evidencia. «Profunda como el mar, en todas partes / del principio que ya fue la huella veo, / y en el destrozo universal que existo, / que existir puedo aun apenas creo» (1872: 8). He subrayado el verbo correspondiente al sentido de la vista. Tassara sostiene también en este contexto su ya expuesta distinción entre mente para pensar y alma o corazón para sentir: «Un principio de vida inagotable / late en mi corazón, piensa en mi mente» (1872: 12). El calificativo inagotable y otros parecidos sirven para enlazar las funciones racionales y sensoriales del hombre con el importante tema al que en último término quiere llegar Tassara. « Naturaleza inmensurable! El hombre / a esta gran sensación no encuentra nombre» (1872: 98). Naturaleza, la divinidad de la llamada teología natural setecentista, es una gran sensación, dice, y se le rinde culto investigándola. En fin, a su modo: «También naturaleza tiene un alma» (1872: 171).

«Ven y muéstrame, ¡oh Dios! y sepa el alma / [...] / que es algo más la eternidad que un nombre, / que hay algo de inmortal y que es el hombre» (1872: 10). « ¡Oh sabia Providencia! yo te adoro. / ¡Oh ciencia, humana ciencia! te desprecio» (1872: 34$)$. Providencia es el nombre que con frecuencia da el deísta a su dios, esa divinidad indiferente que crió el mundo, lo puso en marcha y algún día apretará el otro botón para pararlo todo, sin haber intervenido nunca en la vida del — poco más que hormiga — hombre individual. Aquí escuchamos el angustioso grito del que se da cuenta de que la ciencia de la que él con absurdo optimismo sacó un día un nuevo dios no tardará en destruir todo concepto de divinidad.

Para concluir, he escogido un singular trozo del poema «En el campo», en el que vemos a Tassara volver a desempeñar dos papeles que ya hemos identificado en él: el de maestro de la poética romántica y el de expositor del sentido religioso de la naturaleza. Pues en los versos siguientes tenemos, primero, un buen ejemplo explicativo del panteísmo egocéntrico romántico aplicado a la descripción de la naturaleza; y segundo, derivada directamente de ese esquema, una epifanía naturalista deísta. Es significativa la presencia del sensismo en estos versos; porque tanto el poeta posilustrado sensista como el devoto del culto deísta natural se unen con la naturaleza a través de los sentidos corporales.

\footnotetext{
Gustaba yo del propio sufrimiento en el ajeno padecer. Mi alma esas horas amargas discurría que anhelamos tal vez que todo sienta porque padezca con nosotros todo; y a la pálida flor y al árbol seco daba yo un alma en mi dolor profundo, para tener en mi dolor un eco y consolarme en el dolor del mundo. Un instante no más, y ante mis ojos
} 
se alzó de su letargo el universo

y mi frente a par dél. Mi pecho hería

de agitación vivífica un latido,

y a mi vista un momento confundido

cuanto el orbe en sus ámbitos encierra,

con el fervor del entusiasmo oía

de los cielos la voz llenar la tierra. (1872: 137)

\section{BIBLIOGRAFÍA CITADA}

Bermúdez de Castro, Salvador (1840). Ensayos poéticos. Madrid: El Gabinete Literario.

Castro, Américo (1922). Les grands romantiques espagnols. Paris: La Renaissance du Livre.

Descartes, René (hacia 1925). Discours de la méthode. Ed. d'Alfred Fouillée, Librairie Classique Eugène Belin. Paris: Belin Frères.

Feijoo y Montenegro, Benito Jerónimo (1769). «Paralelo de las lenguas castellana y francesa». Teatro crítico universal. Nueva impresión. Madrid: D. Joaquín Ibarra, Impresor de Cámara de S. M.

García y Tassara, Gabriel (1872). Poesías. Colección formada por el autor, Madrid: Imprenta y Estereotipía de M. Rivadeneyra.

García y Tassara, Gabriel (1878). Corona poética en honor del esclarecido poeta D. Gabriel G. Tassara y algunas poesías inéditas del mismo. Sevilla: Francisco Álvarez y Compañía, Editores.

Glendinning, Nigel (1962). Vida y obra de Cadalso. Madrid: Gredos.

Gullón, Ricardo (1946). «Tassara, duque de Europa», Boletín de la Biblioteca de Menéndez Pelayo. XXII, pp. 132-169.

Méndez Bejarano, Mario (1928). Tassara. Nueva biografía crítica, Madrid: Imprenta de J. Pérez.

Pagés, Juan Antonio (1852). Poesías y escritos literarios y filosóficos. Barcelona: Imprenta y Librería de Oliveros.

Palenque, María (1986). Antología poética de Gabriel G. Tassara. Sevilla: Ayuntamiento.

Peers, E. Allison (1967). Historia del movimiento romántico español. Versión española de José María Gimeno, $2^{\mathrm{a}}$ ed. Madrid: Gredos, dos tomos.

Sebold, Russell P. (2010). Concurso y consorcio: letras ilustrada, letras románticas. Acta salmanticensia: Estudios Filológicos, 329. Salamanca: Ediciones Universidad de Salamanca.

Sebold, Russell P (2003). Lírica y poética en España, 1536-1870. Madrid: Ediciones Cátedra.

Sebold, Russell P. (1970; 1989). El rapto de la mente. Poética y poesía dieciochescas. El Soto, 14. Madrid: Editorial Prensa Española. $2^{a}$ ed. Barcelona: Anthropos.

Sebold, Russell P. (2004). Ensayos de meditación y crítica literaria. Moria, 5, Salamanca: Ediciones Universidad de Salamanca.

Fecha de recepción: 22 de febrero de 2010.

Fecha de aceptación: 1 de septiembre de 2010. 